\title{
Crescimento e marcha de absorção de nutrientes em tomateiro cultivar Raísa cultivado em sistema hidropônico
}

\section{Growth and nutrient absorption by Raisa tomato cultivar grown in hydroponic system}

\author{
Renato de Mello Prado ${ }^{*}$; Victor Honorato Gonçalves Santos ${ }^{2}$; \\ Ancélio Ricardo de Oliveira Gondim³; Adriana Ursulino Alves; \\ Arthur Bernardes Cecílio Filho ${ }^{1}$; Marcus André Ribeiro Correia ${ }^{3}$
}

Resumo

\begin{abstract}
A produção e a qualidade do tomate têm aumentado com o surgimento de novos genótipos e sistemas de cultivo como o hidropônico, entretanto, são poucas as pesquisas sobre a nutrição das plantas. Assim, a presente pesquisa teve o objetivo de avaliar o crescimento e a marcha de absorção de nutrientes pelo tomateiro cultivar Raísa, cultivado em sistema hidropônico. O delineamento experimental adotado foi em blocos casualizados com oito tratamentos constituídos pelas épocas de amostragem: $15 ; 25 ; 35$; $45 ; 55 ; 65 ; 75$ e 85 dias após o transplante (DAT) e cinco repetições. As mudas de tomateiro foram transplantas para vasos de $8 \mathrm{dm}^{3}$, preenchido com substrato a base de fibra de coco, constantemente irrigadas com solução nutritiva de Hoagland e Arnon. Durante o período experimental, avaliaram-se o desenvolvimento das plantas e a matéria seca de folha, caule, frutos e raízes. O acúmulo de matéria seca de folhas e raízes do tomateiro cultivar Raísa foi relativamente mais rápido que os órgãos caule e frutos, ao longo do cultivo, havendo predomínio da matéria seca de frutos $(45 \%)$ em relação às folhas $(27 \%)$, ao caule (24\%) e às raízes ( $3 \%$ ) no final do ciclo da cultura. O acúmulo de macronutrientes e de micronutrientes pelo tomateiro cultivar Raísa teve incremento com ajuste linear ao longo do cultivo, exceto o Mn que foi quadrático. As maiores exigências nutricionais do tomateiro foram $\mathrm{K}, \mathrm{N}$ e Ca para os macronutrientes e de Fe, $\mathrm{Zn}$ e Mn para os micronutrientes.

Palavras-chave: Lycopersicon esculentum Mill, acúmulo matéria seca, desenvolvimento, nutrição de plantas
\end{abstract}

\begin{abstract}
The production and quality of tomatoes has increased with the emergence of new genotypes and cropping systems such as hydroponics, however, there are few studies on the nutrition of plants. The objective was to evaluate the growth and motion of absorption of nutrients by Raisa tomato cultivar, grown in hydroponic system. The experimental design was randomized blocks with eight treatments consisting of the times of sampling: $15,25,35,45,55,65,75$ and 85 days after transplanting (DAT) and five replications. The tomato seedlings were transplanted to pots of $8 \mathrm{dm}^{3}$ (on 31-03-2008), filled with the base substrate of coconut fiber, constantly irrigated with Hoagland and Arnon nutrient solution. During the experimental period and focuses on the development of plants and dry leaves, stems, fruits and roots. The dry matter accumulation of leaves and roots of tomato cultivar Raisa was relatively
\end{abstract}

\footnotetext{
${ }^{1}$ Profs. da Universidade Estadual Paulista Júlio de Mesquita Filho, UNESP, Campus Jaboticabal, Via de Acesso Paulo Donato Castellane, s/n. 14884-900, Jaboticabal, SP, E-mail: rmprado@fcav.unesp.br; rutra@fcav.unesp.br

${ }^{2}$ Graduando em Agronomia da UNESP, Campus Jaboticabal. E-mail: v_honorato@hotmail.com

${ }^{3}$ Programa de Pós-Graduando em Agronomia, Produção Vegetal da UNESP, Campus Jaboticabal. E-mail: anceliogondim@ hotmail.com; adrianaursulino@hotmail.com; marcus.agro@hotmail.com

* Autor para correspondência
} 
faster than the national stem and fruit, over cultivation, with predominance of dry fruits $(45 \%)$ on the leaves $(27 \%)$, the stem $(24 \%)$ and roots $(3 \%)$ at the end of the cycle. The accumulation of nutrients and micronutrients by the tomato cultivar Raisa was fit with linear increase throughout the cultivation, except for Mn which was quadratic. Most of the tomato nutritional requirement for nutrients was $\mathrm{K}, \mathrm{N}$ and $\mathrm{Ca}$ and micronutrients was $\mathrm{Fe}, \mathrm{Zn}$ and $\mathrm{Mn}$.

Key words: Lycopersicon esculentum Mill, dry matter accumulation, development, plant nutrition

\section{Introdução}

O tomate foi introduzido no Brasil a partir de 1940, provavelmente por imigrantes europeus, e atualmente é uma das hortaliças mais cultivadas no país.

O maior produtor mundial é a China, seguida dos Estados Unidos, Itália, Turquia e Egito, dentre outros. Atualmente o Brasil ocupa o sexto lugar no ranking da produção mundial, com uma produção de três milhões de toneladas plantadas em uma área de 57,6 mil hectares (AGRIANUAL, 2008). Em 2007, a soma da produção brasileira de tomate industrial e de mesa foi da ordem de 3,35 milhões de toneladas, com cerca de 56,3 mil hectares plantados. Para o ano de 2008, a estimativa foi da ordem de 3,77 milhões de toneladas a serem colhidas com uma área plantada de 60,4 mil hectares e uma produtividade média de 62,59 t/ha (IBGE, 2008).

Nos dias atuais, para ampliar a produção e qualidade de frutos da cultura do tomate, tem-se utilizado o cultivo protegido. No Brasil, a utilização de ambiente protegido, principalmente para a produção de plantas ornamentais e hortícolas, vem se destacando devido à maior proteção quanto aos fenômenos climáticos, como: geadas, excesso de chuvas, diminuição da temperatura noturna, diminuição de perdas de nutrientes e redução dos custos com fertilizantes e defensivos, enquanto as colheitas nesses ambientes excedem as que se obtêm a céu aberto (OLIVEIRA, 1995; CARRIJO et al., 2004).

Para a sustentabilidade na produção do tomateiro em ambiente protegido é importante atender às exigências nutricionais da cultura, especialmente na época em que ocorre maior demanda por nutrientes, período definido em estudos de marcha de absorção e que podem contribuir para programas de adubação mais eficientes e, conseqüentemente, para maiores produtividades da cultura.

A maioria dos trabalhos que avaliaram a marcha de absorção de nutrientes pelo tomateiro foram desenvolvidos em solo e com materiais genéticos antigos não cultivados atualmente, a exemplo dos trabalhos clássicos como o de Gargantini e Blanco (1963), com a cultivar Santa Cruz 1639, e o de Haag et al. (1978), com a cultivar Roma VF.

Diante disso, esta pesquisa teve o objetivo de avaliar o crescimento e a marcha de absorção de nutrientes pelo tomateiro cultivar Raísa, cultivado em sistema hidropônico.

\section{Material e Métodos}

O experimento foi realizado em estufa agrícola, com laterais abertas, do Setor de Olericultura e Plantas Aromático-Medicinais, da FCAV - UNESP, Jaboticabal, SP, localizado a $21^{\circ} 15^{\prime} 22^{\prime}$ "de latitude sul e 48 18 ' $58^{\prime}$ " de longitude Oeste, na região Norte do Estado de São Paulo.

A semeadura do tomateiro cultivar Raísa foi realizada no dia 04 de março de 2008, em espuma fenólica de 2,5 x 2,5 x 3,8 cm. Após sete dias da emergência(DAE), as plântulas foram transplantadas para canais de polipropileno de $5 \mathrm{~cm}$ de largura com solução nutritiva de Hoagland e Arnon (1950), sem boro e diluída a $25 \%$, em sistema hidropônico tipo fluxo contínuo de nutrientes ("nutrient film technique"; NFT), com recirculação da solução, ficando nessa condição durante uma semana.

O transplante para o local definitivo de cultivo foi 
realizado aos $14 \mathrm{DAE}$, sendo as mudas transplantas para vasos de $8 \mathrm{dm}^{3}$ (uma planta por vaso), preenchido com substrato a base de fibra de coco, frequentemente irrigadas com solução nutritiva de Hoagland e Arnon com $100 \%$ da força iônica.

O delineamento experimental adotado foi em blocos casualizados com oito tratamentos constituídos pelas épocas de amostragem (15;25; $35 ; 45 ; 55 ; 65 ; 75$ e 85 dias após o transplante-DAT) e cinco repetições.

As amostras coletadas foram fracionadas em folha, caule, frutos e raízes, encaminhadas ao laboratório, onde foram submetidas à lavagem conforme indicação de Prado (2008), utilizando água corrente, solução com detergente $(3 \mathrm{~mL} / \mathrm{L})$, água deionizada, solução com $\mathrm{HCl}$ a $0,1 \mathrm{M}$ e água destilada. Posteriormente, foram colocadas em estufa com circulação forçada de ar à temperatura de $65^{\circ} \mathrm{C}$ para determinação de massa seca. Nesta mesma ocasião foram avaliados os parâmetros biológicos indicativos do desenvolvimento das plantas: altura $(\mathrm{cm})$ por meio de uma trena, diâmetro do caule $(\mathrm{mm})$ por meio de paquímetro, número de folhas, número de frutos e área foliar utilizando-se de medidor eletrônico de área foliar, modelo Li-Cor 300. A avaliação dos dados referentes às variáveis: número de frutos e massa seca dos frutos iniciou-se a partir de $35 \mathrm{DAT}$, indicando o início do período de frutificação da cultura. Determinou-se os teores de macronutrientes e de micronutrientes nos diferentes órgãos das plantas (folha, caule, frutos), seguindo a metodologia descrita por Bataglia et al. (1983), e em seguida efetuou-se o cálculo do acúmulo dos nutrientes nos diferentes órgãos das plantas.

Os dados de crescimento da planta e de teor e acúmulo de nutrientes foram submetidos à análise de variância e, havendo significância $(p<0,05)$, realizou-se estudos de regressão polinomial.

\section{Resultados e Discussão}

\section{Crescimento do tomateiro}

Houve incremento com ajuste quadrático em altura (Figura 1a), diâmetro do caule (Figura 1b), número de folhas (Figura 1c) e área foliar (Figura 1d), bem como um incremento com ajuste linear no número de frutos (Figura 1e) em função dos dias após o transplante. Notou-se que a altura das plantas atingiu 181,5 cm aos 85 DAT (Figura 1a), que foi inferior ao obtido por Rodrigues et al. (2002) cultivando tomate em solo, cuja altura das plantas foi de 233,8 cm aos 91 DAT. Esta diferença, provavelmente, deve-se ao tempo distinto de cultivo e a diferença de genótipos. $\mathrm{O}$ crescimento relativamente rápido do tomateiro também foi observado no trabalho de Gargantini e Blanco (1963).

Notou-se que da mesma forma que ocorreu com as variáveis biométricas ao longo do cultivo do tomateiro houve incrementos com ajuste linear no acúmulo de matéria seca de folhas (Figura 2a) e de raízes (Figura 2c), e com ajuste quadrático o aumento na matéria seca do caule (Figura 2b) e de frutos (Figura 2d), o que refletiu na matéria seca da planta inteira (Figura 2e). Aos 85 DAT, houve predomínio da alocação de biomassa nos frutos (45\%) sobre os demais órgãos vegetativos, folhas ( $27 \%)$, caule $(24 \%)$ e raiz ( $4 \%)$, (Figura 2$)$.

O crescimento da planta, expresso pelo acúmulo de matéria seca da planta inteira ao longo do ciclo, foi relativamente lento próximo aos 30 dias após o transplante (DAT), sendo que maiores incrementos ocorreram a partir dessa época até o final do ciclo (Figura 2e). Haag et al. (1978) observaram que o crescimento do tomate industrial foi lento até os 30 dias, havendo crescimento acelerado após, com a massa seca da planta inteira dobrando a cada quinzena no período dos 45 aos $75 \mathrm{DAT}$, atingindo o máximo com 105 DAT. 

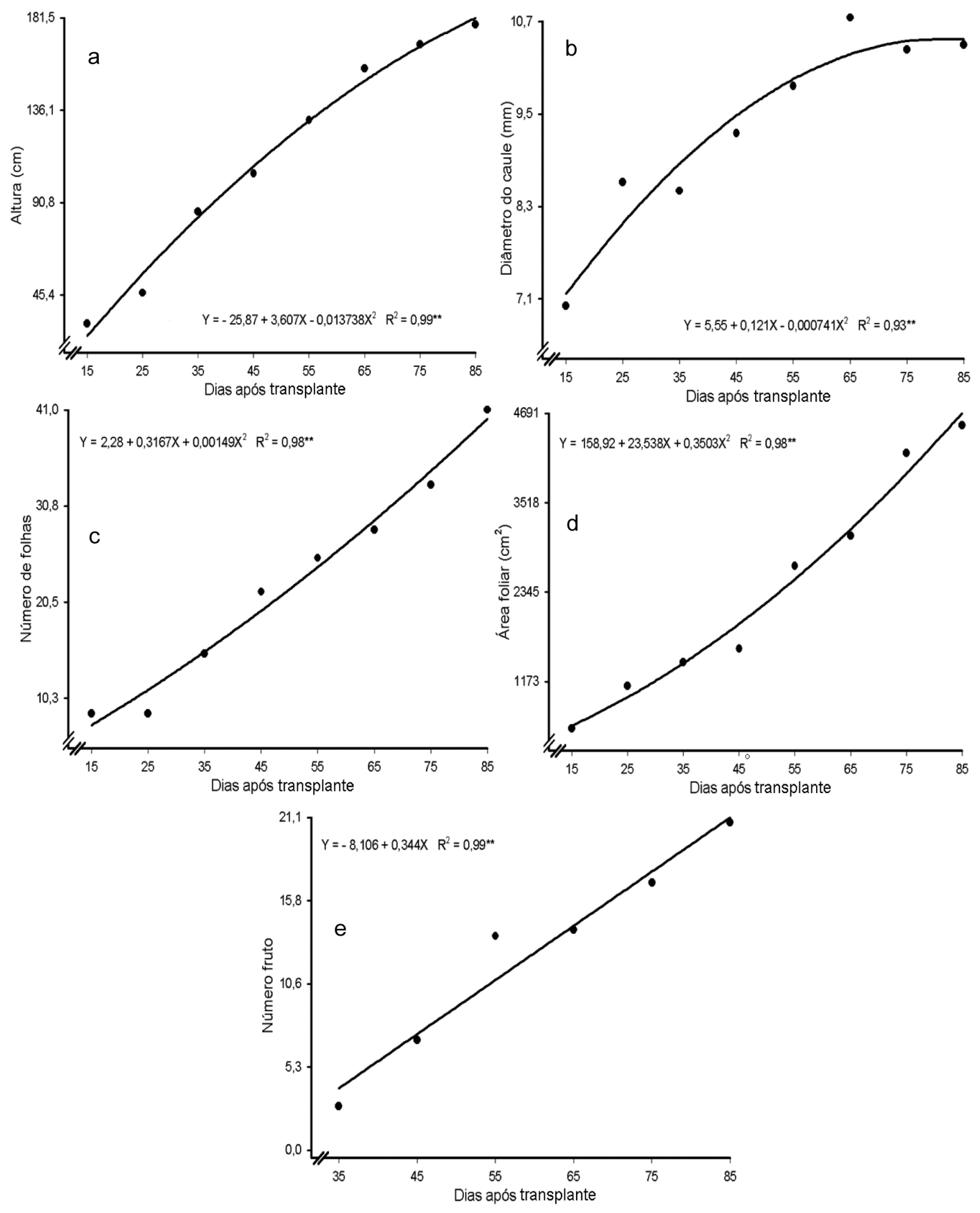

Figura 1. Altura (a), diâmetro do caule (b), número de folhas (c), área foliar (d) e número de frutos (e) em tomate cultivar Raísa N, cultivado em sistema hidropônico. FCAV-UNESP, Jaboticabal. SP. 2008. 

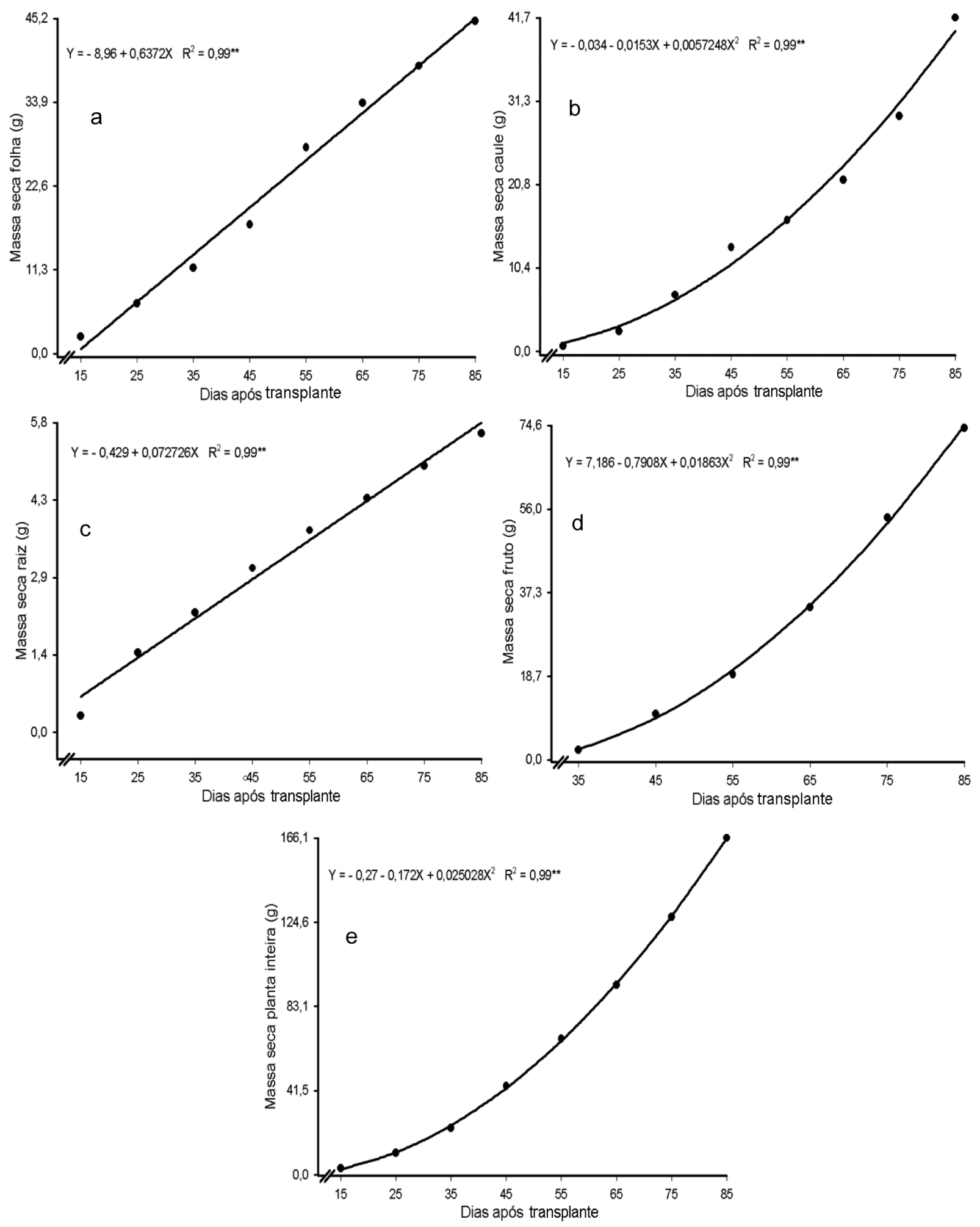

Figura 2. Matéria seca de folha (a), caule (b), raiz (c), frutos (d) e planta inteira (e) do tomateiro cultivar Raísa N, cultivado em sistema hidropônico. FCAV-UNESP, Jaboticabal. SP. 2008. 
Teor e acúmulo de nutrientes nas folhas, caule e raizes do tomateiro

Em função do tempo de cultivo, apenas os teores de $\mathrm{N}$ e $\mathrm{K}$ nas folhas do tomateiro apresentaram decréscimo com ajuste linear, enquanto os teores dos macronutrientes secundários $\mathrm{Ca}, \mathrm{Mg}$ e $\mathrm{S}$ aumentaram linearmente, e o teor de $\mathrm{P}$ não foi influenciado pelo tempo de cultivo (Figura 3a). Houve incremento com ajuste linear no acúmulo dos macronutrientes nas folhas do tomateiro ao longo do cultivo (Figura 3b). O decréscimo dos teores de $\mathrm{N}$ e $\mathrm{K}$ nas folhas ocorreu possivelmente pelo efeito diluição, pois o acúmulo desses nutrientes foi crescente ao longo do ciclo da cultura. Observou-se para os teores dos micronutrientes nas folhas do tomateiro, um incremento para o teor de Fe com ajuste quadrático e diminuição com ajuste quadrático nos teores de Mn e Zn, enquanto os teores de $\mathrm{Cu}$ e $\mathrm{B}$ não foram afetados em função do tempo de cultivo (Figura 3c). Notou-se um incremento com ajuste linear no acúmulo dos micronutrientes nas folhas do tomateiro, exceto os teores de Fe e Mn que aumentaram com ajuste quadrático ao longo do cultivo da hortaliça (Figura 3d). Salienta-se que os teores dos nutrientes nas plantas ao longo do ciclo, seguem diferentes modelos polinomiais, indicando que as variações são dependentes do nutriente que é influenciado pela velocidade de absorção e sua interação com a taxa de crescimento da planta.

Para o caule, observou-se decréscimo com ajuste quadrático para o teor de $\mathrm{N}$ e $\mathrm{P}$, e ajuste linear para o teor de $\mathrm{K}$ e um acréscimo com ajuste quadrático nos teores dos macronutrientes secundários nesse órgão do tomateiro ao longo do cultivo (Figura 4a). Constatou-se incremento com ajuste linear no acúmulo dos macronutrientes no caule do tomateiro ao longo do cultivo, exceto o $\mathrm{Ca}$ e $\mathrm{S}$ que exibiram aumento com ajuste quadrático nesse órgão (Figura 4b). Para os teores dos micronutrientes, observou- se apenas decréscimo nos teores, com ajuste linear para o teor de Fe e ajuste quadrático nos teores de $\mathrm{B}$ e $\mathrm{Zn}$ no caule ao longo do cultivo da hortaliça (Figura 4c). Houve um incremento com ajuste linear no acúmulo dos micronutrientes no caule do tomateiro ao longo do seu cultivo (Figura 4d).

Notou-se incremento com ajuste linear para os teores de $\mathrm{Ca}$ e $\mathrm{Mg}$ e ajuste quadrático no teor de $\mathrm{P}$, e um decréscimo com ajuste linear nos teores de $\mathrm{Ne}$ de $\mathrm{K}$ da raiz do tomateiro ao longo do cultivo (Figura 5a). Houve um incremento dos macronutrientes na raiz do tomateiro ao longo do cultivo (Figura $5 b$ ). Com relação aos teores dos micronutrientes nas raízes do tomateiro verificou-se um aumento com ajuste linear para o Fe e Zn, ajuste quadrático para $\mathrm{Cu}$ e B, e decresceram com ajuste linear no teor de Mn desse órgão (Figura 5c). Notou-se incremento com ajuste linear no acúmulo dos micronutrientes nas raízes do tomateiro, exceto para o $\mathrm{B}$, que teve aumento quadrático (Figura 5d).

Teor e acúmulo de nutrientes nos frutos e na planta do tomateiro

Para os teores dos macronutrientes nos frutos do tomate, notou-se decréscimo apenas no teor de $\mathrm{K}$ desse órgão ao longo do cultivo, enquanto para os demais nutrientes, houve incremento com ajuste quadrático (Figura 6a). Assim, houve incremento com ajuste linear no acúmulo dos macronutrientes dos frutos de tomate, exceto o Ca que teve aumento com ajuste quadrático (Figura 6b). Para os teores dos micronutrientes nos frutos, observou-se decréscimo linear para $\mathrm{Cu}$ e $\mathrm{B}$, e um acréscimo com ajuste quadrático para o Mn e Zn (Figura 6c). Observou-se um acréscimo com ajuste linear no acúmulo dos micronutrientes do fruto do tomate ao longo do cultivo, exceto o $\mathrm{Zn}$ que apresentou ajuste quadrático (Figura 6d). 
(a)

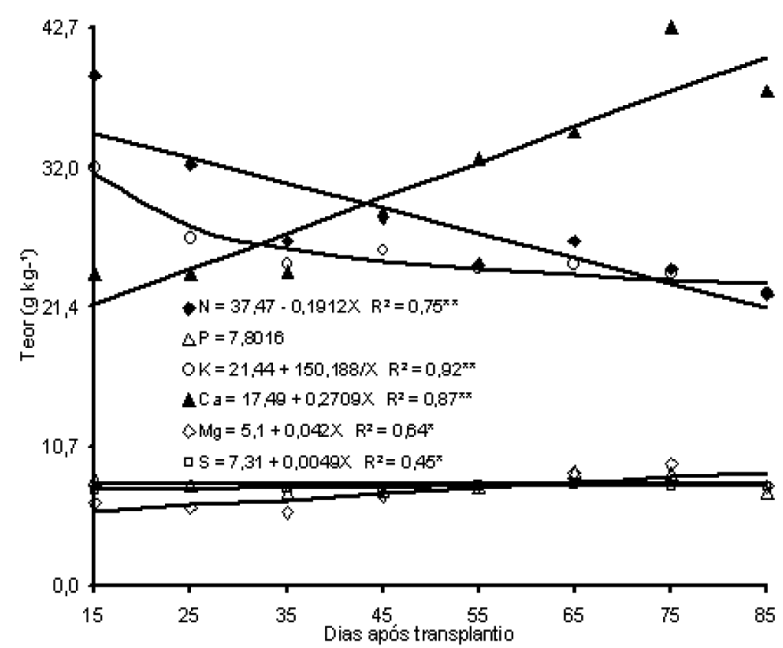

(c)

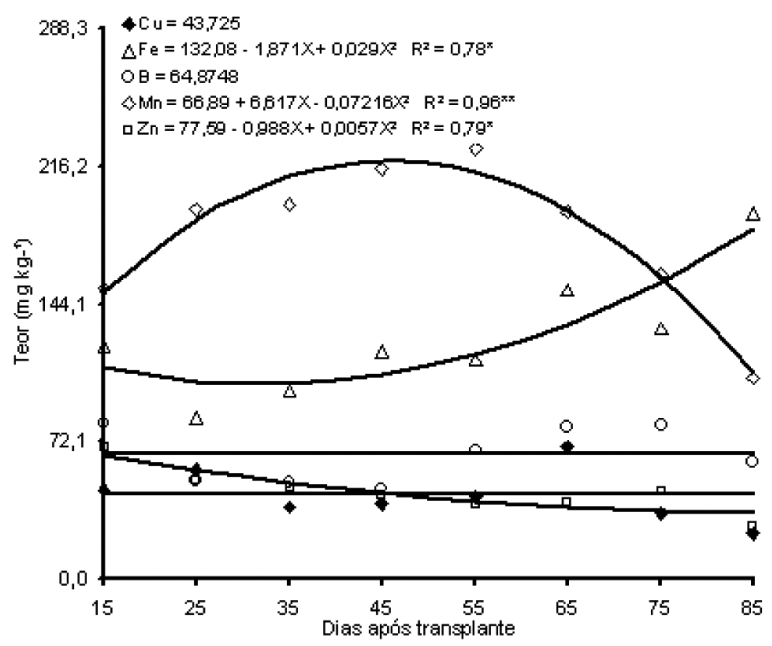

(b)

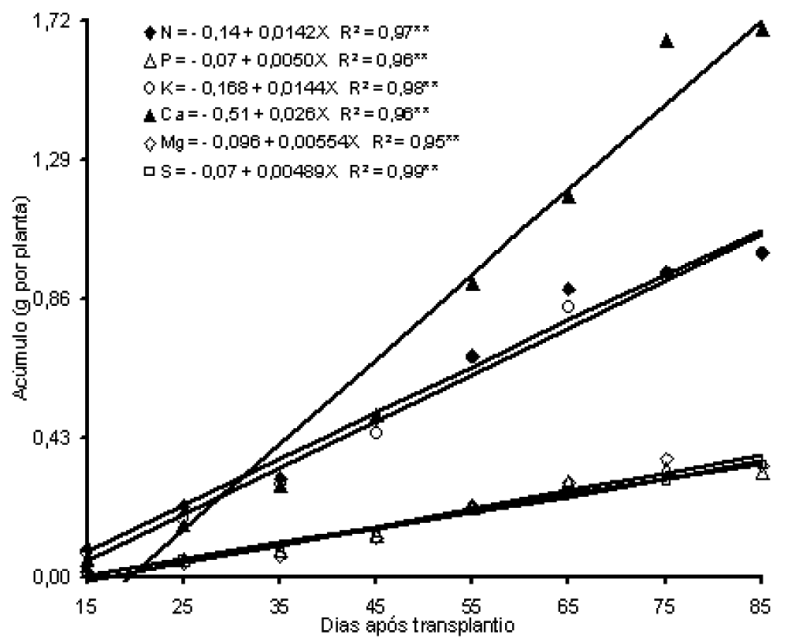

(d)

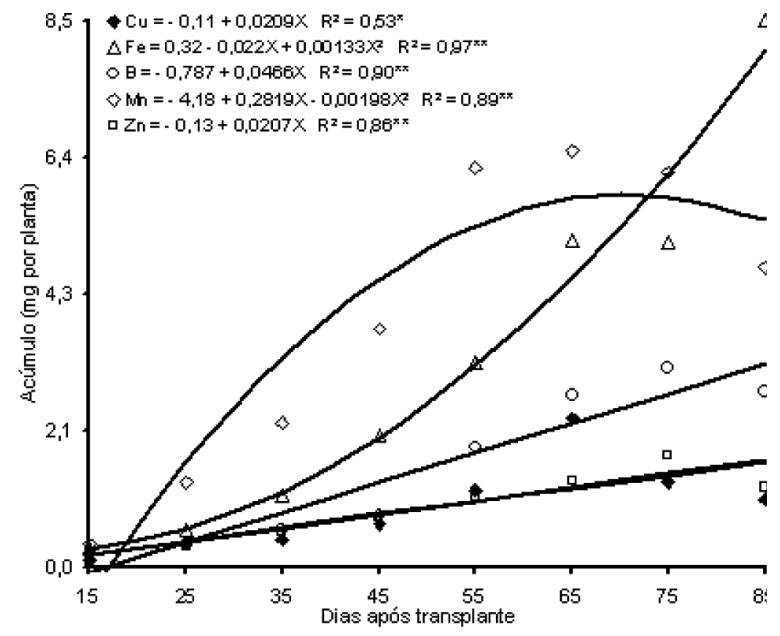

Figura 3. Teor (a) e acúmulo (b) dos macronutrientes e teor (c) e acúmulo (d) de micronutrientes nas folhas de tomateiro cultivar Raisa N, cultivado em sistema hidropônico. FCAV-UNESP, Jaboticabal. SP. 2008. 
(a)

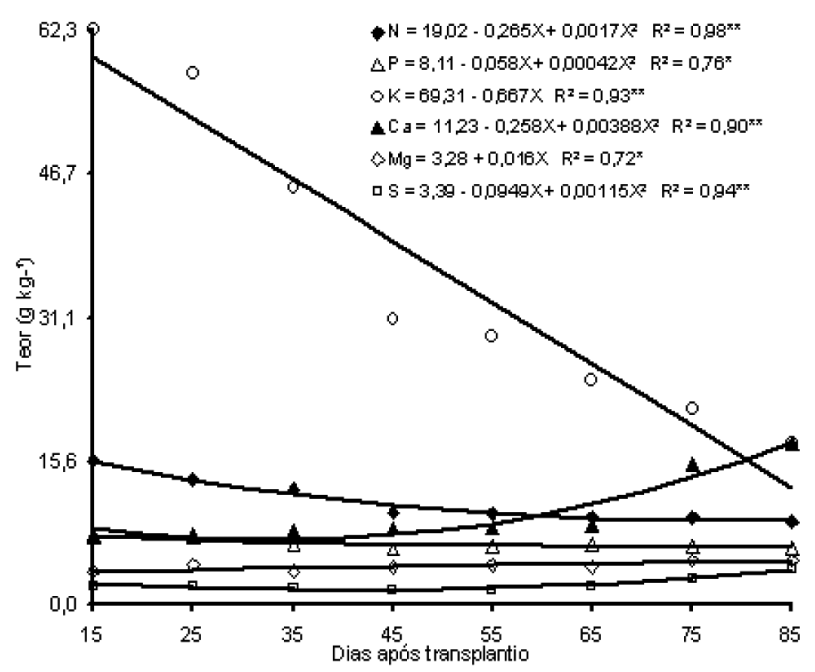

(c)

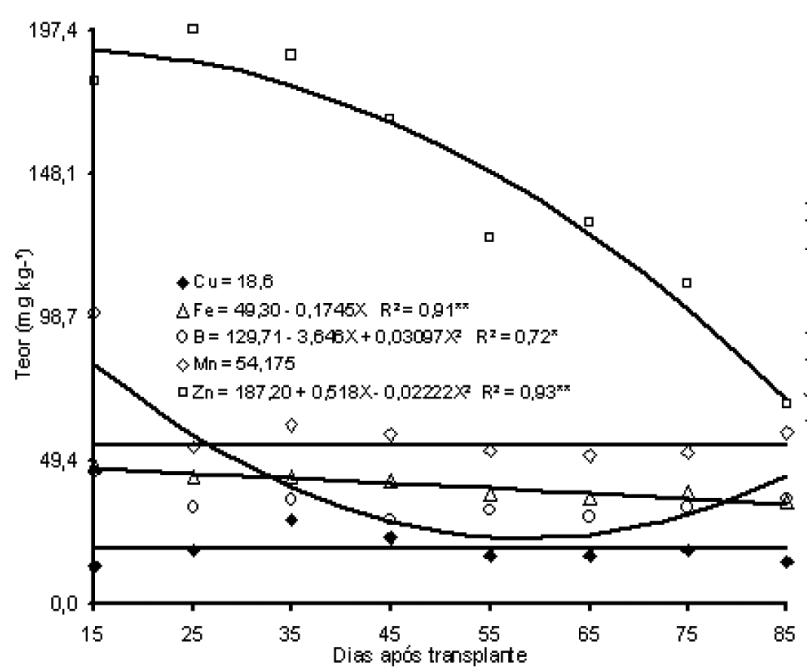

(b)

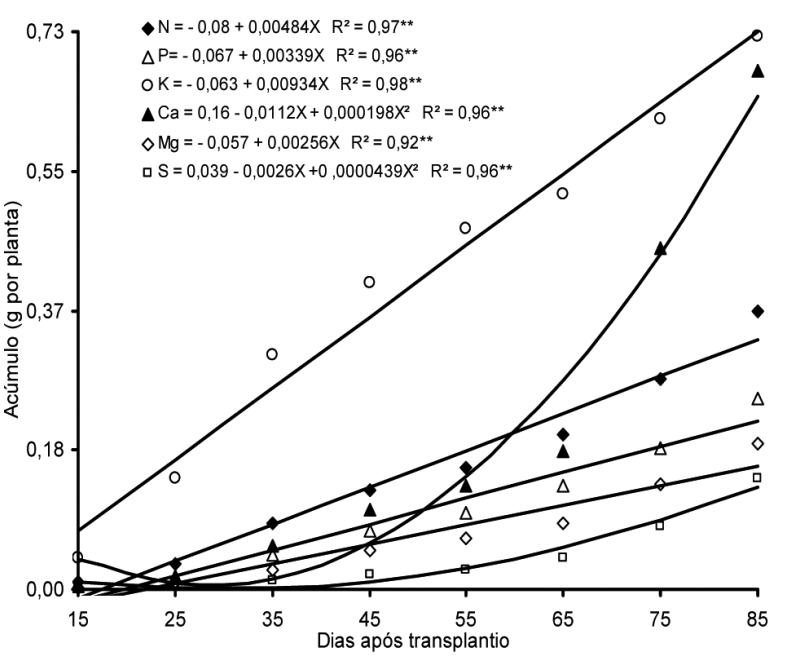

(d)

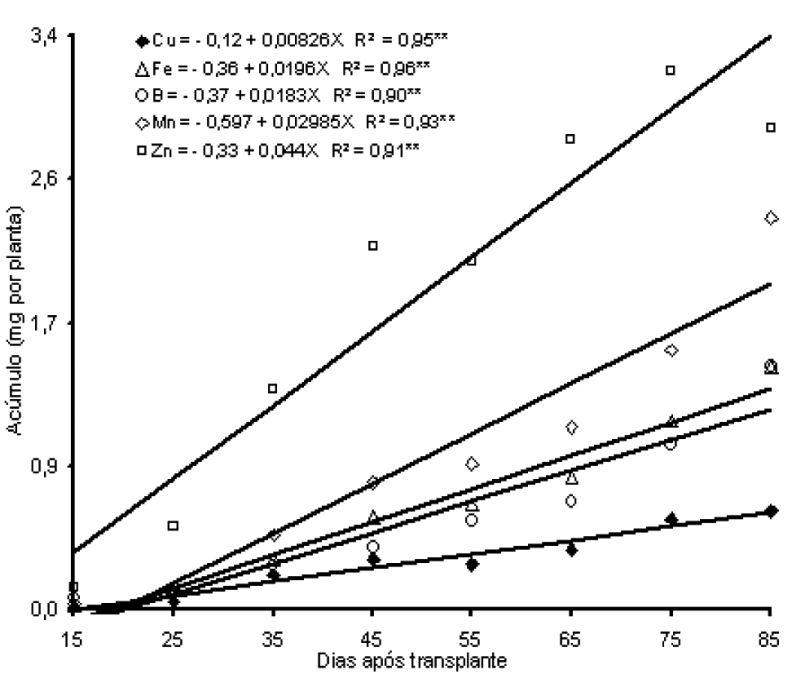

Figura 4. Teor (a) e acúmulo (b) dos macronutrientes e teor (c) e acúmulo (d) dos micronutrientes nas no caule do tomateiro cultivar Raisa N, cultivado em sistema hidropônico. FCAV-UNESP, Jaboticabal. SP. 2008. 
(a)

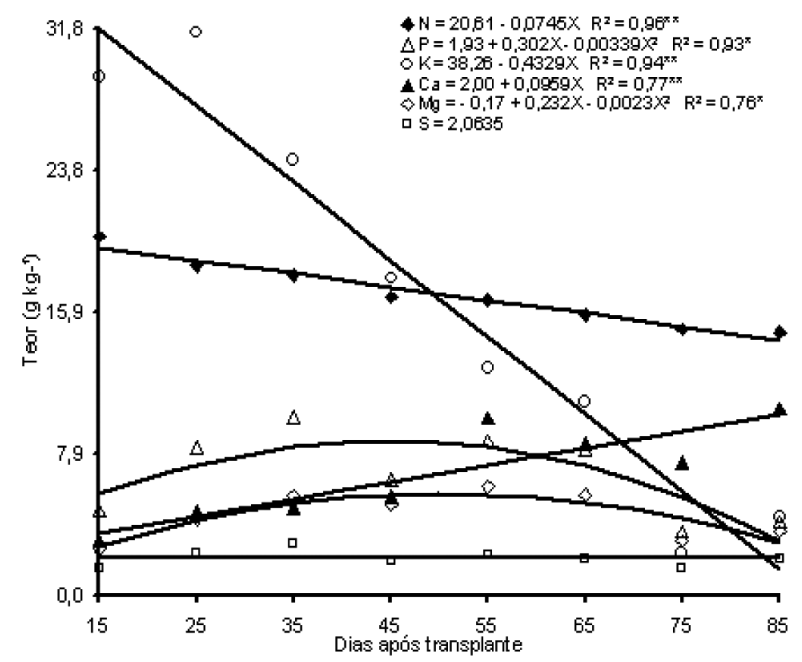

(c)

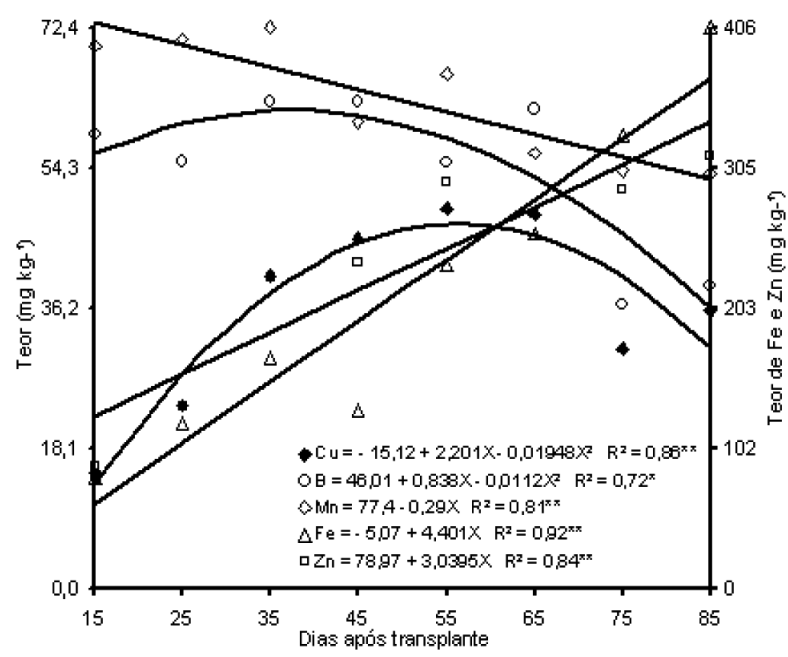

(b)

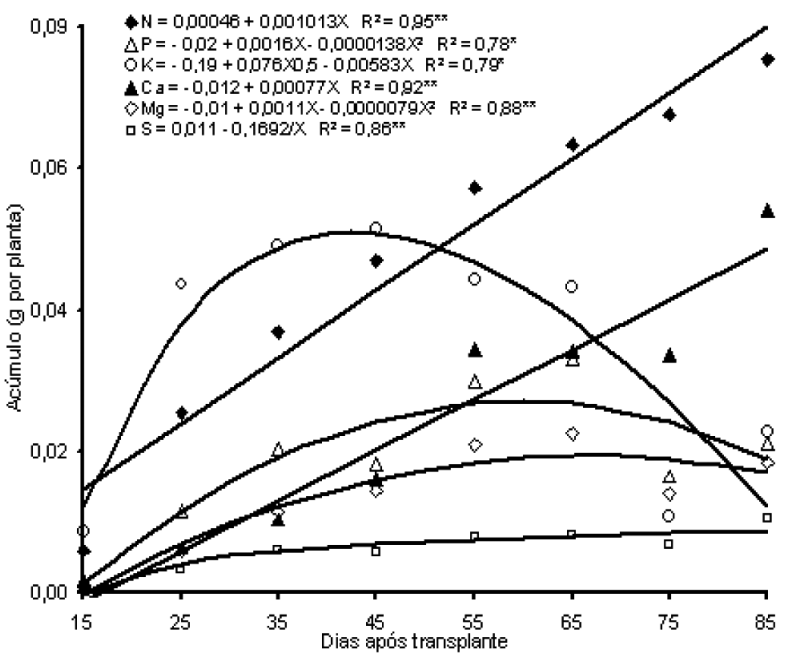

(d)

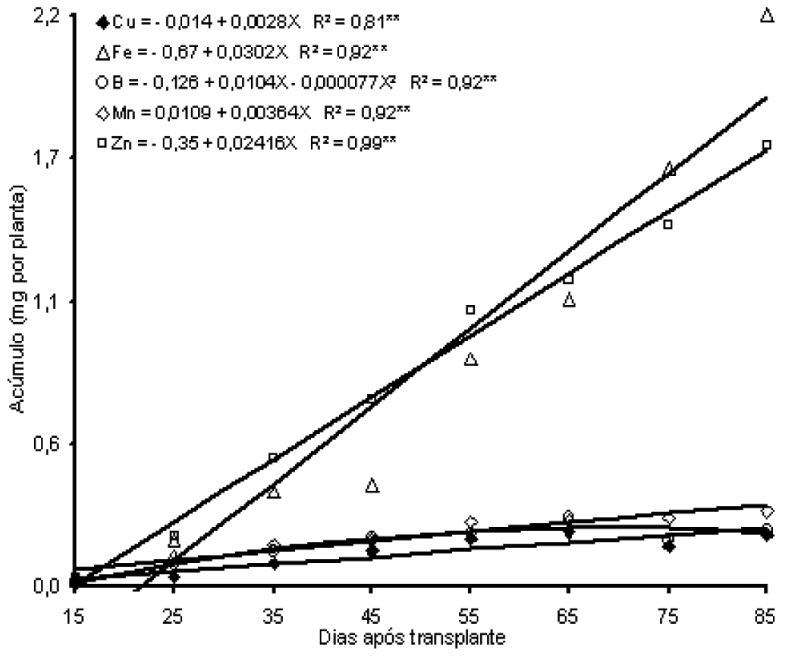

Figura 5. Teor (a) e acúmulo (b) dos macronutrientes e teor (c) e acúmulo (d) de micronutrientes das raízes do tomateiro cultivar Raisa N, cultivado em sistema hidropônico. FCAV-UNESP, Jaboticabal. SP. 2008. 
(a)

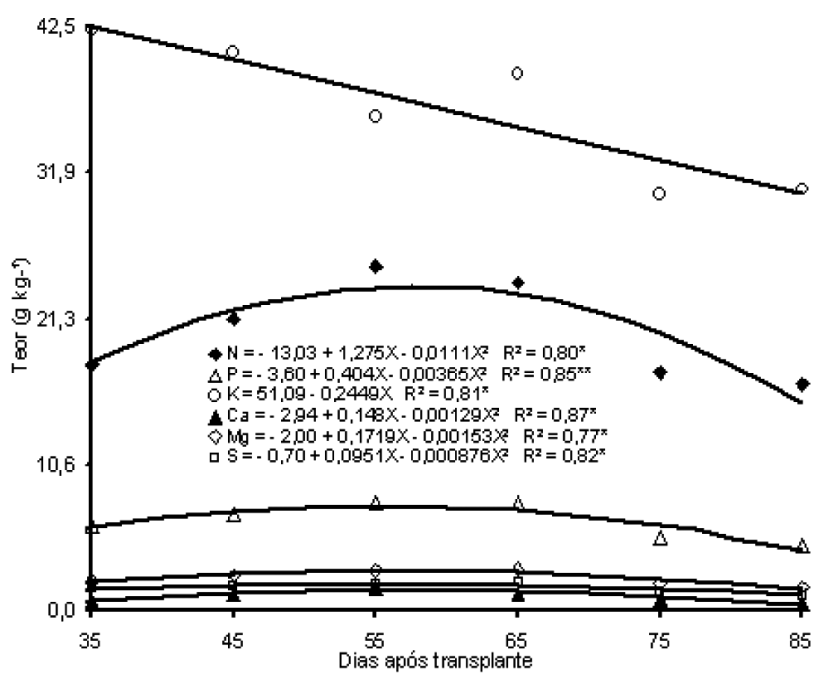

(c)

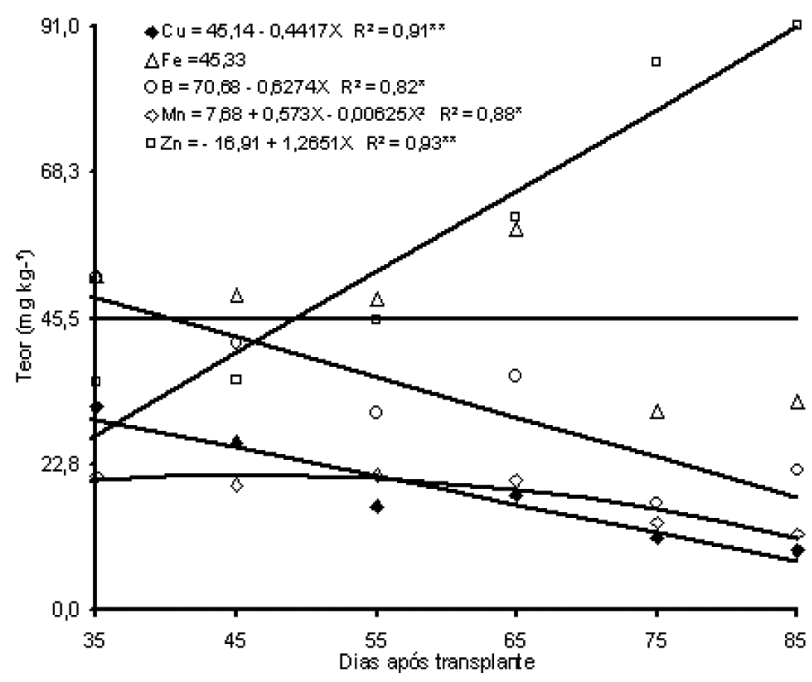

(b)

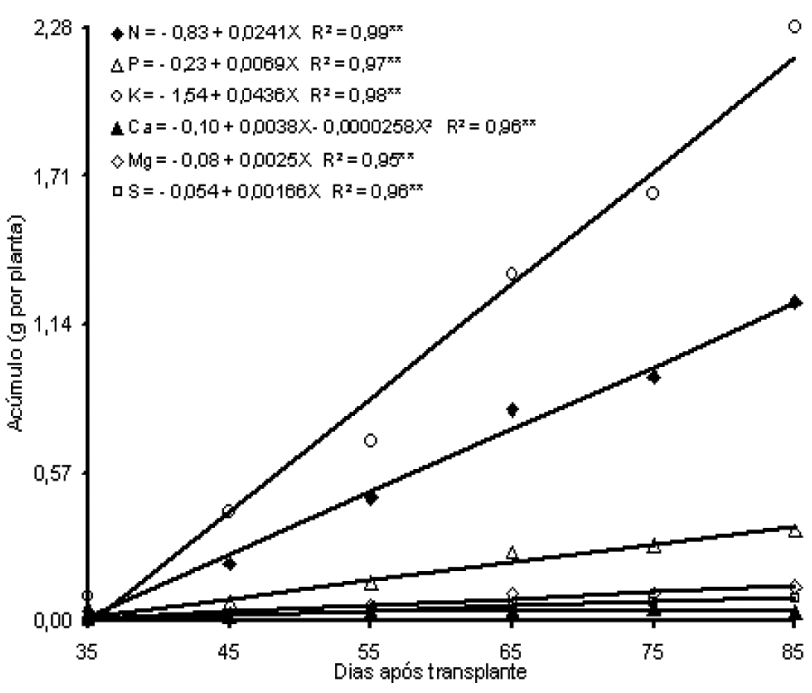

(d)

Figura 6. Teor (a) e acúmulo (b) dos macronutrientes e teor (c) e acúmulo (d) de micronutrientes dos frutos do tomateiro cultivar Raisa N, cultivado em sistema hidropônico. FCAV-UNESP, Jaboticabal. SP. 2008.

Houve um incremento com ajuste linear no acúmulo dos macronutrientes e dos micronutrientes na planta inteira do tomateiro ao longo do cultivo (Figura 7a), exceto no caso do Mn, que teve aumento com ajuste quadrático (Figura $7 b$ ).

No final do ciclo da cultura, aos 85 dias após o transplantio, notou-se que o acúmulo de nutrientes na planta se apresentaram em proporções variáveis nos diferentes órgãos da planta. $\mathrm{O}$ acúmulo de

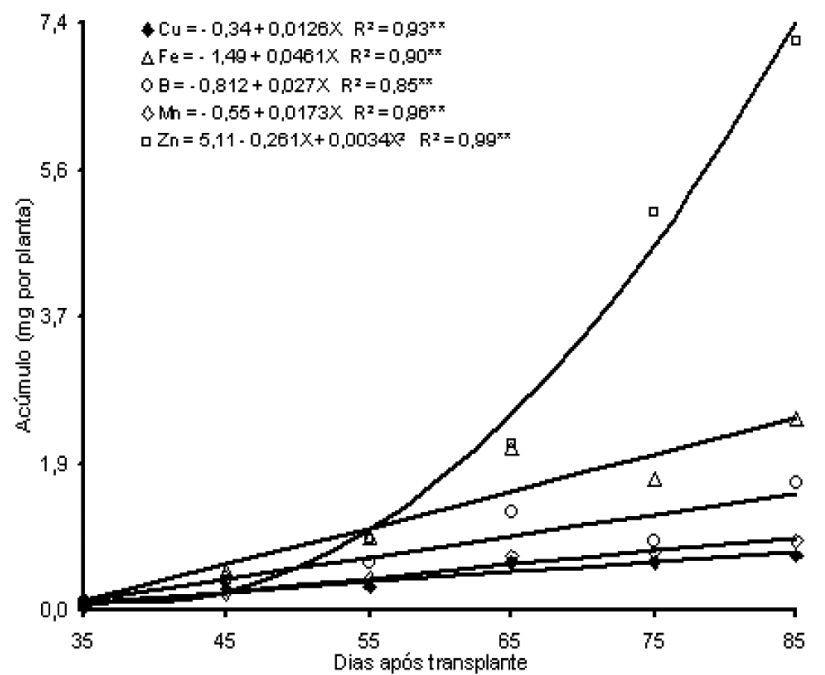

potássio pela hortaliça foi de $3,8 \mathrm{~g}$ por planta $(76,0$ $\mathrm{kg} \mathrm{ha}^{-1}$ ) (Figura 7a), tendo a seguinte distribuição nos órgãos folhas, caule, raízes e frutos: $27 ; 18 ; 1 \mathrm{e}$ $54 \%$, respectivamente. O nitrogênio foi o segundo nutriente mais acumulado pelo tomateiro cultivar Raisa, atingindo um máximo de 2,61 g por planta $\left(52,2 \mathrm{~kg} \mathrm{ha}^{-1}\right)$ (Figura 7a), tendo distribuição nas folhas, caule, raízes e frutos: $40 ; 12 ; 3$ e $45 \%$. O acúmulo de fósforo foi de $0,943 \mathrm{~g}$ por planta $(18,86$ $\mathrm{kg} \mathrm{ha}^{-1}$ ) (Figura 7a), tendo distribuição nas folhas, 
caule, raízes e frutos: $37 ; 23 ; 2$ e $38 \%$. Notouse que os nutrientes $\mathrm{K}, \mathrm{N}$ e $\mathrm{P}$ apresentaram maior concentração no órgão fruto, o que concorda com resultados obtidos por Fayad (1998). O acúmulo de cálcio foi de 2,32 $\mathrm{g}$ por planta $\left(46,4 \mathrm{~kg} \mathrm{ha}^{-1}\right)$, atingido aos 85 DAT (Figura 7a), tendo a seguinte distribuição nas folhas, caule, raízes e frutos: 70; 26; 2 e 2\%, respectivamente. $\mathrm{O}$ acúmulo de $\mathrm{Mg}$ na planta foi de $0,68 \mathrm{~g}$ por planta $\left(13,6 \mathrm{~kg} \mathrm{ha}^{-1}\right)$, com participação nas folhas, caule, raízes e frutos de 55; 23; 3 e 19\%. Halbrooks e Wilcox (1980) também observaram que o $\mathrm{Ca}$ e o $\mathrm{Mg}$ concentramse mais nas folhas do tomateiro. $\mathrm{O}$ enxofre foi o

(a)

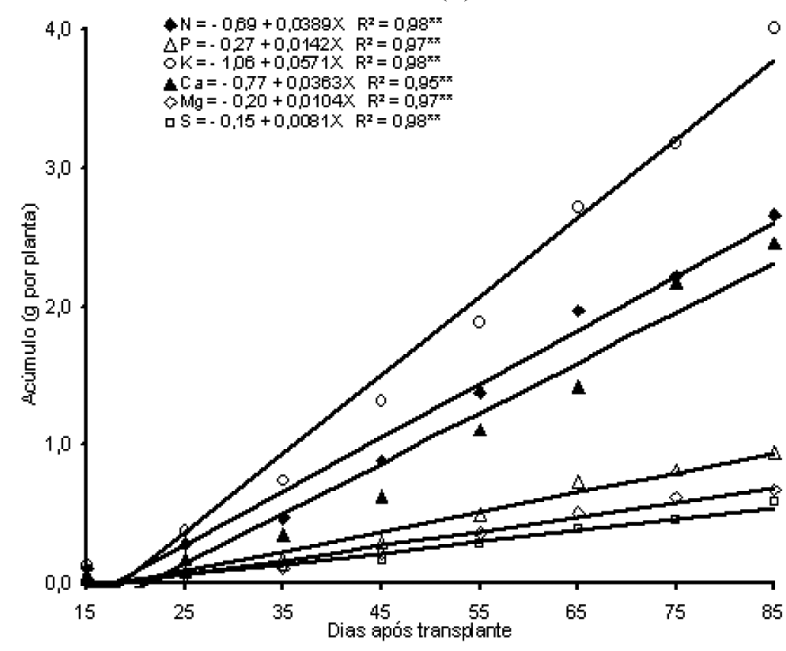

macronutriente de menor acúmulo pela cultura do tomateiro, com um máximo de 0,54 g por planta $\left(10,8 \mathrm{~kg} \mathrm{ha}^{-1}\right)$ (Figura 7a), concentrando nas folhas a maior parte deste macronutriente $(60 \%)$, em comparação ao caule $(23 \%)$, às raízes $(2 \%)$ e aos frutos (15\%). Portanto, notou-se que a ordem de extração dos macronutrientes pelo tomateiro em cultivo hidropônico foi $\mathrm{K}>\mathrm{N}>\mathrm{Ca}>\mathrm{P}>\mathrm{Mg}>\mathrm{S}$ enquanto, Haag et al. (1978), em experimento de campo notaram que o $\mathrm{K}, \mathrm{N}$ e $\mathrm{P}$ foram os nutrientes mais extraídos pela cultura. Esta diferença na ordem de extração dos nutrientes mais acumulados nos frutos, possivelmente deve-se ao fator genético dos materiais e do meio de cultivo distintos.

(b)

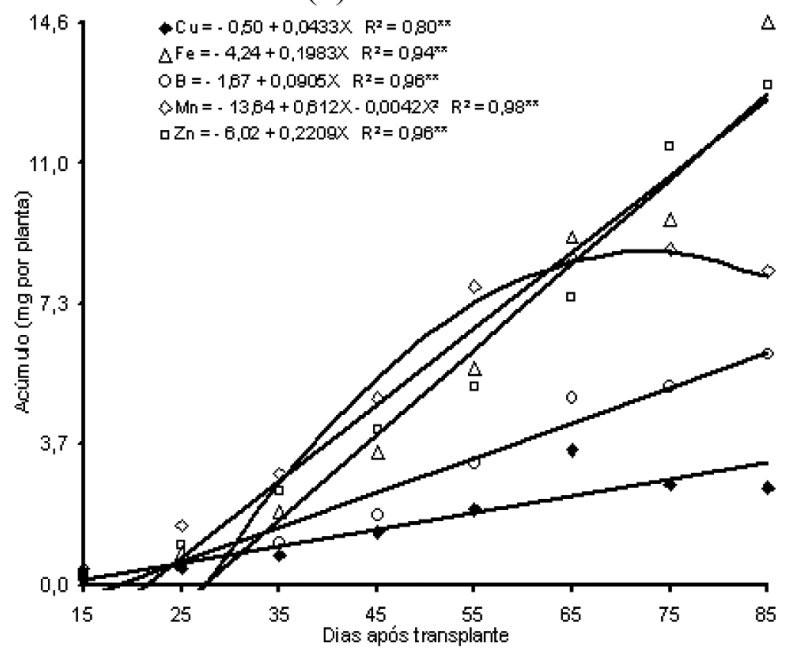

Figura 7. Acúmulo de macronutrientes (a) e de micronutrientes (b) na planta inteira do tomateiro cultivar Raisa N, cultivado em sistema hidropônico. FCAV-UNESP, Jaboticabal. SP. 2008.

No final do ciclo do tomateiro, observou-se que o acúmulo de boro pela cultura foi de $6,0 \mathrm{mg}$ por planta $\left(0,12 \mathrm{~kg} \mathrm{ha}^{-1}\right)$ (Figura $\left.7 \mathrm{~b}\right)$, concentradose especialmente nas folhas (52\%), em relação aos demais órgãos da plantas como caule (20\%), raízes $(3 \%)$ e frutos $(25 \%)$. O acúmulo de cobre pela cultura, foi de $3,18 \mathrm{mg}$ por planta $(0,064 \mathrm{~kg}$ ha $^{-1}$ ) (Figura 7b), sendo que as folhas contribuíram com a maior parte (52\%), em comparação a caule $(18 \%)$, raízes $(7 \%)$ e frutos $(23 \%)$. O acúmulo de ferro pela cultura do tomateiro, foi de $12,61 \mathrm{mg}$ por planta $\left(0,25 \mathrm{~kg} \mathrm{ha}^{-1}\right)$ (Figura $\left.7 \mathrm{~b}\right)$, e novamente as folhas contribuíram com a maior parte (58\%), em detrimento de caule $(10 \%)$, raízes $(14 \%)$ e frutos (18\%). O acúmulo de manganês pela cultura foi de $8,04 \mathrm{mg}$ por planta $\left(0,16 \mathrm{~kg} \mathrm{ha}^{-1}\right)$ (Figura $7 \mathrm{~b}$ ), concentrados nas folhas $(63 \%)$ em relação a caule $(22 \%)$, raízes $(4 \%)$ e frutos $(11 \%)$. O acúmulo de zinco foi de $12,76 \mathrm{mg}$ por planta $\left(0,25 \mathrm{~kg}^{\mathrm{h}} \mathrm{ha}^{-}\right.$ 1) (Figura 7b), concentrando-se a maior parte nas folhas $(63 \%)$, em detrimento aos demais órgãos da planta, como caule $(22 \%)$, raízes $(4 \%)$ e frutos $(11 \%)$. 
Portanto, o acúmulo dos micronutrientes aos 85 dias após o transplantio apresentou a seguinte seqüência decrescente: $\mathrm{Fe}=\mathrm{Zn}>\mathrm{Mn}>\mathrm{B}>\mathrm{Cu}$. Nota-se diferença entre esta ordem de extração de micronutrientes e aqueles encontradas por outros autores como, Fernandes et al. (1975) $(\mathrm{Fe}>\mathrm{Mn}>\mathrm{Zn}>\mathrm{B}>\mathrm{Cu})$ e Rodrigues et al. (2002) $(\mathrm{Mn}>\mathrm{Fe}>\mathrm{Zn}<\mathrm{Cu}>\mathrm{B})$, entretanto, houve semelhança àquela indicada por Castellane (1982) em que indicou que os dois micronutrientes mais exigidos pelo tomateiro foram o Fe e o $\mathrm{Zn}$. As diferenças de extração dos nutrientes pelo tomateiro entre este trabalho e os de outros autores possivelmente se devem a fatores de produção distintos como sistema de cultivo e genótipos.

\section{Conclusões}

O acúmulo de matéria seca de folhas e raízes do tomateiro cultivar Raísa foi relativamente mais rápido que o de outros órgãos, como caule e frutos, ao longo do cultivo, havendo predomínio da matéria seca de frutos $(45 \%)$ em relação às folhas $(27 \%)$, caule $(24 \%)$ e raízes $(4 \%)$ no final do ciclo da cultura.

$\mathrm{O}$ acúmulo de macronutrientes e de micronutrientes pelo tomateiro cultivar Raísa teve incremento com ajuste linear ao longo do cultivo, exceto no caso do $\mathrm{Mn}$, que apresentou ajuste quadrático.

As maiores exigências nutricionais do tomateiro foram de K, N e Ca para os macronutrientes e de Fe, $\mathrm{Zn}$ e Mn para os micronutrientes.

\section{Referências}

AGRIANUAL 2008. FNP. Consultoria e comércio. Anuário da agricultura brasileira. São Paulo, 2007.

BATAGLIA, A. C.; FURLANI, A. M. C.; TEIXEIRA, J. P. F.; FURLANI, P. R.; GALLO, J. R. Métodos de análise química de plantas. Campinas: Instituto Agronômico, 1983. 48 p. (Boletim Técnico, 78).

CARRIJO, O. A.; VIDAL, M. C.; REIS, N. V. B.; SOUZA, R. B.; MAKISIMA, N. Produtividade do tomateiro em diferentes substratos e modelos de casas de vegetação. Horticultura Brasileira, Brasília, v. 22, n. 1, p. 5-9, 2004.

CASTELlANE, P. D. Nutrição mineral da cultura do tomateiro (Lycopersicon esculentum, Mill): I. Efeitos dos nutrientes na qualidade dos frutos. In: MULLER, J. J. V.; CASALI, V .W. D. (Ed.). Seminários de olericultura. Viçosa: UFV, 1982. v. 3, p.113-157.

FAYAD, J. A. Absorção de nutrientes, crescimento e produção do tomateiro cultivado em condições de campo e estufa. 1998. Dissertação (Mestrado em Agronomia) Universidade Federal de Viçosa, Viçosa.

FERNANDES, P. D.; CHURATA-MASCA, M. G. C.; OliveIRA, G. D. de; HAAG, H. P. Nutrição de hortaliças: XXVII. Absorção de nutrientes pelo tomateiro (Lycopersicum esculentum Mill.) em cultivo rasteiro. Anais da Escola Superior de Agricultura "Luiz de Queiroz, Piracicaba,v. 32, p. 595-607, 1975.

GARGANTINI, H.; BLANCO, H. G. Marcha de absorção de nutrientes pelo tomateiro. Bragantia, Piracicaba,v. 22, n. 1, p. 693-714,1963.

HAAG, H. P.; OLIVEIRA, G. D.; BARBOSA, V.; SILVA NETO, J. M. Marcha de absorção de nutrientes pelo tomateiro (Lycopersicon esculentum Mill), destinado ao processamento industrial. Anais da Escola Superior de Agricultura "Luiz de Queiroz", Piracicaba,v. 35, n. 2, p. 243-269, 1978.

HALBROOKS, M.; WILCOX, G. E. Tomato plant development and elemental accumulation. Journal American Society Horticultural Science, Alexandria, v. 105, n. 6, p. 826-828, 1980.

HOAGLAND, D. R.; ARNON, D. I. The water culture method for growing plants without soils. Berkeley: California Agricultural Experimental Station. 1950. 347 p.

INSTITUTO BRASILEIRO DE GEOGRAFIA E ESTATISTICA. - IBGE. SIDRA 2008: Sistema de recuperação automática. Rio de Janeiro: Instituto Brasileiro de Geografia e Estatística, 2008. Disponível em: <http://www.sidra.ibge.gov.br>. Acesso em: 25 nov. 2008.

OLIVEIRA, M. R. V. O emprego de casas de vegetação no Brasil: vantagens e desvantagens. Pesquisa Agropecuária Brasileira, Brasília, v. 30, n. 8, p. 1049-60, 1995.

PRADO, R. M. Nutrição de plantas. São Paulo: Editora UNESP, 2008. v. 1, 407 p.

RODRIGUES, S. D.; PONTES, A. L.; MINAMI, K.; DIAS, C. T. S. Quantidade absorvida e concentrações de micronutrientes em tomateiro sob cultivo protegido. Scientia Agricola, Piracicaba, v. 59, n. 1, p. 137-141, 2002. 